\title{
LLTI Highlights
}

\section{LLTI Highlights}

\section{Ute S. Lahaie \\ Gardner-Webb University}

Welcome to the "LLTI Highlights." This is a special moment for this column in a time of transition. As we are publishing the last printedition of the IALLT journal and are looking forward to a brand-new electronic journal, we are anticipating many changes yet to be determined by the new journal editor. This means that this column may not continue in its current format. It has been a great pleasure for me to serve as columnist for the journal from 2001 until this final print edition of the journal. I would like to thank all the IALLT members who have contributed to the electronic discussions on language learning and technology. The discussion topics posted on the LLTI listserver have covered a broad spectrum of topics, ranging from technical 'how-to' instructions, over pedagogical exchanges, to discussions dealing with various realities of the language technology professionals themselves. Over the years, this column has featured a selection of important electronic discussions from the LLTILanguage Learning and Technology International-list server. The discussions of this column were posted during the first half of the year 2006 and have been summarized and paraphrased by me. Otmar Foelsche, the moderator of the electronic discussion list, has assigned a reference number to each topic that appeared in the discussion list. This number can be used to search the LLTI archives. Instructions on searching the archives appear at the end of this column.

None of the January discussions were very long. It was interesting to observe, however, that the most fruitful discussion of the month focused on the use of old technology. Mike launched the discussion on with the following: "John de Szendeffy reported similar problems:"Our Hypercard-type applications also did not survive the transition from Mac OS 10.3 to 10.4 (running in Classic). For example, John McVicker's fine NewReader application. While NewReader could import text files in the unrestricted Finder, we could not tweak permissions for it to open them in MCX (Managed Client for OS X), which is our authentication/document server environment in our labs." One of the problems I have had with HyperCard stacks (and the X-Media templates are HyperCard based) has to do with the way $\mathrm{HC}$ stacks run. HyperCard instructions are interpreted as they run. Often the cpu is so fast that the next instruction starts 'running' before the previous line of code finishes. My solution to this is to insert wait commands in the code itself.If you can find the line that causes the error and insert 'wait 1 secs' without quotes 
before it, it may solve your problem. Then again, are you using any software that works from the 1990's......" Derek Roff joined in: "We successfully run several very old Hypercard and Hypercard-derived programs under Classic in Mac OS 10.4.3 and 10.4.4. Some of these did not work under 10.4.0 thru 10.4.2, but started working again with the upgrades around 10.4.3. QuickTime also went through some upgrades in the same period, which could have been a factor. If you haven't tried the newest, or nearly newest versions of Tiger and QuickTime, it might be worth the experiment." Keola Donaghy added "A word of caution for those of you using apps in Classic mode, like Hypercard: Classic will not run under the new Intel-powered Macs. At least that's what I have been told by my friends within Apple......."

A February discussion on Online Work and Tenure Review (\#8163) was initiated by Franz-Josef Wehage with the following: "How do other colleges/universities look at online work (website development) as an integral part of promotion and tenure?" Mike Ledgerwood replied: "To be quite frank it varies enormously from institution to institution. It depends upon the quality of work, the quantity of work, and the work's context as well. Finally, it also depends upon whether the work is part of the requirements of the position and/or whether this type of work was listed in the job description the candidate initially applied to......" Another response came from Michael Jones: "In discussions here at Swarthmore, the Provost has basically said that the standards, would be much the same as for books and traditional scholarship. The Committees on tenure and promotion would be looking for scholarly material, in whatever form, that moves scholarship in a particular field forward. She didn't see the need for the development of explicit criteria for online work ... which of course probably does litthe to encourage non-traditional work. One person to contact for her experience would be Barbara Nelson at Colby College, who received a promotion to full Professor last year based on a Dossier that consisted largely of online work." Joel Goldfield suggested: "You might want to take a look at the Modern Language Association's online "Guidelines for Evaluating Work with Digital Media in the Modern Languages" at <http://www.mla.org/guidelines_evaluation_digital>. The MLA might also be able to supply the names of faculty and institutions that have tackled this issue after consulting with that organization. The following document may have been updated since it was ratified by the CALICO membership on March 16, 2001: Scholarly Activities In Computer-Assisted Language Learning: Development, Pedagogical Innovations, And Research. Joint Policy Statements of CALICO, EUROCALL, AND IALLT Arising from a Research Seminar at the University of Essen, Germany30 April-1 May 1999......" A very detailed response came 
from Bob Peckham: "I introduced my campus to this concept. Traditionally our scholarship has been 'peer reviewed.' But recently this has led to shamefully poor quality publications (in other words, the traditional system of peer review is dysfunctional). I do more and more things outside this framework. Evaluations are public acceptance, good reviews from traditional reviewing journals, newspapers, cyber review sources, such as MERLOT, and comments from web site users. Yes I have to demonstrate the acceptance of my work. Some of you who are familiar with my Foreign-Language Software \& Web Central, which is available at <http://webpages.charter.net/tbob/softwrev.html>, will know that there are organizations which evaluate educational web sites for language learning, such as

- Blue Web'n (reviews of foreign language education sites) $<$ http://www.kn.pacbell.com/wired/bluewebn/contentarea.cf m?cid $=6>$,

- EDsitement (foreign languages) <http://edsitement.neh.gov/tab_lesson.asp?subjectArea=2>, Education World Foreign (Language Site Reviews) $<\mathrm{http}: / /$ www.education-world.com/awards/past/topics/lang arts.shtml\#Foreign\%20Languages>

- I Love Languages <http://www.ilovelanguages.com/>

- MERLOT - World Languages <http://www.merlot.org/artifact $/$ BrowseArtifacts.po?catcode $=318$ \&browsecat $=317>$ [.......].

I had a very good review in 2004 for Societe Francois Villon <http://www.utm.edu/staff/globeg/villon.shtml>. This site is also a 'signet de la Bibliotheque Nationale de France' and is now cited by most book-length studies on Villon. I also have some five-star MERLOT sites. When it comes time for yearly evaluation, I simply give an update of my web work and receive my points. I keep up with page view stats......." Read Gilgen referred to IALLT resources on this issue: "You might also want to view two official IALLT statements... not directly addressing online work, but outlining professional responsibilities for our profession, and addressing the scholarly natureof....... Go to the IALLT website at <http://www.iallt.org/about_iallt/official_documents.html>.

Katia Carraro initiated a March discussion on Laptops \& Sanako Lab 300 (\#8171) in the end of February with the following: "We would like to set up a new language lab with laptops and the Sanako lab 300. Does anyone have experience with this kind of equipment and installation? Is there something we should know before we venture into this project? We don't intend to use laptops to go wireless. 
The main reason why we're thinking about laptops is because the room is also going to be used for other purposes and we don't want to have monitors on the way." A first response came from Jack Burston: "An alternative to using laptops to avoid having monitors in the way would be to use LCD screens that fold down. Desktop computers (stored under the table top) are less expensive, and offer more internal expansion room (for RAM, hard disks, video capture cards, etc.) than laptops. I've seen folding LCD screens advertised, but don't know just how flat they will go. Perhaps someone on this listserv can point you (and me) in the right direction." Stacey L. Powell made another useful recommendation: "If you want to investigate the possibility of desktop computers that 'disappear' when you don't need them, I highly recommend looking at the Hide-Away desks from Computer Comforts $<$ http://www.computercomforts.com $>$. We have a classroom full of these desks (with computers on them) and I can't say enough good things about them......" Tom Griffin raised security concerns: "Sanako Lab 300 is a hardware-assisted digital language lab. It uses a separate network cable to send audio and coaxial cable to send video. Audio and network should not be a problem since their headsets go into a separate box that connects both of these cables. However, a video capture card at each student station is needed to capture video and view live video streams from the instructor station. If you go without student capture cards you are limited to already digitized files for viewing video at each student station. Sanako Lab 300 is one of the three vendors bidding on our lab upgrade. We are however, using Dell Optiplex desktops so PCI or PCI Express video capture cards go in rather easily. There are external USB and internal but removable PC card slot video capture hardware devices available, but the portable nature of such labtop oriented accessories requires them to be external or removable, thus an inherent security risk. In choosing a USB video card, check with Sanako and also make sure it can be physically padlocked, chained, glued or otherwise fastened to the PC or furniture to avoid theft. The Sanako Headset Adapter should also be somehow secured. Furniture, like that from Synsor has hidden compartments to put in hardware. We chose desktops because of the security issue. You can lock the case with a padlock so nobody can get to the goodies inside." Gus Leonard added: "Yes, 300 is the hardware/software tool. But Sanako also has the 1200 lab which is IP based, similar to the Forum 100,but I don't have any hands-on experience."

An April discussion on Screen Captures for video production (\#8205) was launched by David Pankratz with the following: "We are producing some 'how to' videos in which we want to demonstrate how to use certain web pages. The best way to do this seems to be to perform 'screen captures', using applications that make 
movies out of a sequence of actions you perform at your computer, which then allows you to show that movie to somebody else. We will be delivering these little movies online. We are rookies, and are fighting with issues like image quality, flickering of the final compressed sequences........Does anybody have any recommendations for this process, for example which capturing software has worked for you, any tips for rookies, and so forth?" A first recommendation came from Sue Otto: "We have been using TechSmith's Camtasia Studio and like it a lot. Not only have we been producing software tutorials, but a number of our doctoral students have used it for data collection for their dissertations. This is a Windows application. Their website is: <http://www.techsmith.com/>.They have some other capture products as well." Sherri Reed and Ed Dente concurred with Sue's recommendation. Henry Wilmer added: "Captivate (formerly Robodemo) has worked well for us." Bill Koulopoulos had another suggestion: "We have used a fabulous program called SnapzProX2 that not only captures screen shots but also captures video. In my opinion it is the best thing in the market for the price. By the way, it is a Mac OSX program. You can find it at the following URL: <http://www.ambrosiasw.com>." John de Szendeffy added: "You didn't mention what platform you're working on, so I don't know if you can use Ambrosia Software's Snapz Pro X 2, for Mac OS X (\$69). It is a great screen movie capture utility that we use to make lab training videos....... To use a screen capture such as this one successfully, you need to understand optimal resolution and color settings and choose the right export codec for the video. The manual usually covers these topics well. We export our screen capture video to DV format then edit that in Final Cut Pro for pretty good results. We export the finished video using the H.264 codec for LAN delivery. (H.264 requires a pretty fast processor to render on playback, so your computer needs to be less than 3 years old or so. Marlene Johnshoy joined in: "I have been hearing really good things about Macromedia's Captivate from people in my instructional design grad class, but haven't used it myself." Thomas Plagwitz: "And then there is windows media encoder 9(http://www.microsoft.com/windows/windowsmedia/forpros/enc oder/default.mspx). It does not have all the features of the dedicated documentation generators (I have used Camtasia and Robodemo, now Captivate). But I have not experienced any of the problems you mention with the windows media video 9 screen codec that it uses for screen videos. And it has a price tag that will be hard to beat (it is free for xp)." A suggestion for a free solution came from Vito Brondolo: "CamStudio is similar to Camtasia but it is freeware. You can download it from the following site: $<$ http://sourceforge.net/projects/camstudio/>.

A May discussion on Language Podcasts (\$8222) was started in 
April by Alison Sommer with the following query: "I am looking for recommendations of good podcasts in German, French, Russian, Japanese and Spanish. They don't need to be specifically focused on language instruction, I just want some well done and interesting podcasts in those languages so that I can make them available to our students and faculty......." Chen Xiaobin suggested: "You may go to Podcastalley.com and search the keyword 'Deutsch' and get a whole list of German podcasts." Another recommendation came from Read Gilgen: "We have a couple of very well done podcasts here at the University of Wisconsin, in German and in Spanish. The podcasts can be accessed at the following URLs: <http://spanport.lss.wisc.edu/newsite/podcasts/>, and <http://german.lss.wisc.edu/podcast/>.Ralph Schultz joined in: "The French Pod Class is incredible. I also love a 'Spoonful of Russian'. For simple basic Spanish, I like Spanish Arriba's Podcast......." Alexandre Rafalovitch: "......I just found this one and it sounds good: <http://www.international.ucla.edu/languages/technology/podcasts/businessrussian/ $>$. A related question came from Tracy Dingess: "A tech trivia question: I have a freeware podcast client (Lime) and I have it pointed to an $\mathrm{xml}$ page with feeds (files various languages). I figure I can hack the 'genres' of the client and relabel as languages. However, I have no expertise or idea what to do to keep my students from downloading all new podcast items regardless of language. If I succeed in getting the client to display categories as 'languages' will students be able to download one category/language? Has anyone met a client or developed a solution to this idea/problem? I would welcome input." Margo Burns responded to this new query: "It sounds like you need to make different 'channels' in your feed for the different languages, so students of a particular language subscribe to just the channel they need...." Tracy Dingess replied: "Yes, I have done that with the original rss.xml files on the servers, one for each class or language. Students can take their personal computers and program/teach their own clients to collect from the language feed/channel(s) of their choice. However, the point I am considering, don't know if it can be done, is to make a client on a PUBLIC MACHINE segregate the languages it collects by language and have students be able to go to a list in that client for only the language they desire......." Todd Bryant suggested: "It might be easiest to just organize the rss feeds with folders live bookmarks for each language in firefox."

Erin Fallon initiated aproductive June/July Discussion on Facility Artwork (\#8271) with the following: "We are in the process of renovating our Multi-Media facility and I'd really like update the art work on the walls.Might anyone know of a vendor that offers some interesting technology pieces......?" Luz Forero responded: "We just renovated our language center, so I understand your dilemma. My 
colleague...... and I decided that for at least one of ourlabs we would have a photography contest for our students. The winners will have their work displayed for a year. If your multi-media facility is interdisciplinary, this is a nice way to tie it all in and have student involvement. Why not put some flyers up around campus (and the arts department) or put an announcement on your website to get students involved? You can make up rules about sizing, format, the medium, and the submittal process that make sense for your space and you can put together a team of judges from different disciplines [......]. If you come up with a theme that will entice students to think about technology and education, you might get the nice side-effect of student engagement...." Nina Garrett added: "I don't know about technology pieces, but when we moved into our newly renovated facility I decided I didn't want travel posters from other countries but rather great art from other countries. The Yale Art Gallery gives out good reproductions to University buildings doing that. I persuaded a local vender to give me a good price on frames, and they look really nice......." Brenda Bertrand agreed: "We are just setting up our center and I also decided against the travel posters.......We're going to go with pictures of our students overseas and blow up the best photographs into poster size. As we get a good collection, we'll start a photo contest and only keep the winning photograph(s) each year. This should give us a very nice collection that will keep changing with our student body." Jose Rodriguez: "Not necessarily artwork as you've requested, but just to give you another idea... we decorate our language lab walls with plaques of students who we honor each year for excellence in language study (in each of our 18 languages) and also with framed portraits of our language teachers of the year. The portraits are professionally done in their classrooms, so they have a very candid, active feel to them. Students have commented that they like seeing their teachers recognized this way." Judy Shoaf: "I love the idea of student travel photos. I did that some years ago by chance but hadn't thought of a contest.......I made some pictures of my own when we were getting renovated 5 years ago: French Inaction (a dreamy Picasso lady with a TV remote in her hand), Murasaki Laptop (fabulous Japanese dame trailing a laptop showing azaleas on her kimono), L'E-liseuse (Fragonard's reading girl in yellow with an e-book), Smalley Tapes (Munch's Scream with headset and vowels in the sky), and the Tree of Knowledge, CD-Rom (CDs replacing the apples in a Cranach Adam and Eve). This was fun and kept me sane, though for some reason nobody notices them any more than if they were travel posters. Daniel Tom: "About a year ago we renovated our labs and took down the travel posters and redecorated. We also asked faculty, staff and students to submit cultural photos from their travels and had them blown up and mounted on quarter-inch thick Styrofoam 
poster board. They are not framed. The contest idea is great. However, we did not have one, and the person doing the decorating was the sole decision maker on what photos to use...." Dick House's suggestion focused on student-generated artwork: "Our answer to travel $[\ldots . .$.$] was to begin putting student-painted murals on the$ walls. So far, we have a completed German representation and plan for a French entry. We shocked the University Architect by asking in advance if this was permitted and what 'rules' there might be to painting over University walls. The answer was rather straightforward and involved getting pro forma 'permission' from our Dean and following some very simple guidelines as to type of paint. Consulting with the various programs has resulted in suggestions for the actual contents of the murals." Ralph Schultz: "I am just letting you all know. I am a painter. My website is < www.people.virginia.edu/ $\sim \operatorname{ras} 2 n>$. My latest work is not up, but you can get an idea of what I do. So if you have a wall that you can not over and you like my work, call me and I can loan you some art. Another suggestion came from Sue Otto: "Our Center walls are covered with flags (3' $x$ 5 ' sized ones) from countries that speak the languages we teach at the University of Iowa. They look great and have drawn really positive comments from lots of people. Visitors and new students invariably stand there and try to name the countries the flags represent. This tradition got started when one of our student lab attendants, who collected international flags, bequeathed a few of his duplicates to the Language Media Center when he graduated. Inspired by this, I went out and bought a bunch from a local store to hang when we moved into our new space; and more have been acquired since then. We don't have all the flags we own up at once (not enough wall space); so we rotate them from time to time. The last flags I purchased were from Southwest Imports (<http://www.swimport.com $/>$ ) and they were exceptionally inexpensive......." Margo Burns: "In my last lab, we had wallpaper with a map of the world on one entire wall. It always got great comments." To this Ed Dente added: "Which reminds me that the map display that always draws the most interest is the one displaying the world from south at top to north at bottom (i.e., 'upside down') rather than the traditional way [......]." This posting resulted in a new query from Nina Garrett: "Where can one get the 'upside down' map? There was a wonderful West Wing episode about that, in which CJ was lectured by a group calling themselves 'Geographers for Social Equality', who argued that having North America and Europe at 'the top' and Africa and Latin America at 'the bottom' privileged the more developed countries......." Margo Burns pointed out some sources: "South up' maps are pretty popular in Australia! <http://www.flourish.org/upsidedownmap/>,<http://www.odt.org/southupmaps.htm>......"

The discussions of the Language Learning and Technology 


\section{LLTI Highlights}

International (LLTI) list server have been archived and posted on the web. These LLTI archives can be accessed from the IALLT Home page, which is located at < http://www.iallt.org/>. A link to the LLTI list server appears at the top level of the IALLT Home page. The LLTI list server page gives instructions on how to subscribe or unsubscribe to the list server. In addition, there is a link to the LLTI archives. These archives can also be directly accessed at <http://listserv.dartmouth.edu/archives/liti.html $>$.

To search the archives, type the subject in the first search field. The search engine will match the subject with the subject headings of the archived messages. You may also type a key word or words in the second search field. This search will look for the key words in the body text of all messages. It the reference number that has been assigned to a discussion topic is entered in this field, the search will bring up a complete list of all discussions dealing with the topic. You may also want to restrict search by limiting it to a specific author or by entering beginning and ending dates. Such a restriction is particularly useful for searches on frequently occurring topics. Any questions or comments related to the LLTI list server may be addressed to Otmar Foelsche, the moderator of the LLTI discussion list. Otmar can be contacted at otmar.foelsche@dartmouth.edu.

Ute S. Lahaie is Associate Professor of German at Gardner-Webb University. She serves on the IALLT Board as Secretary/Parliamentarian. 